Research Article

\title{
Knowledge and Practices about Malaria in Two Tribal Dominated Regions of Madhya Pradesh, India
}

\author{
Vinay Tripathi', Preetha GS \\ ${ }^{1}$ Associate Professor, ${ }^{2}$ Professor, IIHMR Delhi, Sector 18-A, Dwarka, New Delhi, India. \\ DOI: https://doi.org/10.24321/0019.5138.202146
}

\section{I $\quad \mathbf{N} \quad \mathbf{F} \quad \mathbf{O}$}

\author{
Corresponding Author: \\ Vinay Tripathi, IIHMR Delhi, Sector 18-A, Dwarka, \\ New Delhi, India. \\ E-mail Id: \\ vinaytripathi@gmail.com \\ Orcid Id: \\ https://orcid.org/0000-0002-9367-1457 \\ How to cite this article: \\ Tripathi V, Preetha GS. Knowledge and Practices \\ about Malaria in Two Tribal Dominated Regions \\ of Madhya Pradesh, India. J Commun Dis. \\ 2021;53(3):112-117. \\ Date of Submission: 2021-07-14 \\ Date of Acceptance: 2021-09-03
}

\section{$\begin{array}{llllllll}\mathbf{A} & \mathbf{B} & \mathbf{S} & \mathbf{T} & \mathbf{R} & \mathbf{A} & \mathbf{C} & \mathbf{T}\end{array}$}

Given the substantial contribution tribal population makes to the overall malaria load in the country, their role is important in the malaria elimination context. Assimilation of correct malaria preventive and care seeking behaviour among them, thereby, becomes very critical. Community level knowledge and practices regarding malaria can reflect on the extent of this assimilation. A cross-sectional survey of 482 randomly selected households was conducted in Umaria and Dindori districts of Madhya Pradesh using a semi-structured schedule to assess the community level knowledge and practices with respect to the causation, transmission, prevention and treatment of malaria. Descriptive statistics are used to determine relative frequencies and percentages. Chi-square test is used to determine the associations between the variables. Majority of the respondents (71.2\%) were aware of the role of mosquitoes in the transmission of malaria. However, only $30 \%$ of the respondents reported the most characteristics symptoms of malaria, i.e., "fever with chills". The awareness about transmission and symptoms was associated with educational status of the respondents as well as history of malaria infection. $65 \%$ of the households were using mosquito net bed and $57 \%$ burnt foliage/cow dung cakes to protect themselves from mosquitoes. Out of all the malarial cases, $61 \%$ sought treatment from government health facilities, while remaining from private facilities. Findings indicate that tribal groups generally possessed knowledge about malaria and engage in desirable behaviours for its management and control pointing towards their acceptance and assimilation of the government programme.

Keywords: Knowledge, Practices, Behaviour, Malaria, Tribal, India

\section{Introduction}

The world had an estimated 228 million cases of malaria and 4, 05,000 malaria deaths in 2018. ${ }^{1}$ Majority of these cases and deaths were reported from WHO African region and South-East Asia Region with the South-East Asia region alone reporting 8 million cases and 11,600 malaria deaths. India contributed to $58 \%$ of total reported cases in the region. ${ }^{2}$ The data of past two decades of the country indicate a declining trend in malaria burden. The number of malaria cases in India has declined from 2.08 million (in 2001) to 
about 8.4 lakhs (in 2017), ${ }^{3}$ while the mortality has declined from 932 (in 2000) to 562 (in 2014) to 194 (in 2017). .,5 However, despite the progress, states with high incidence of malaria continue to pose challenges towards achieving the goal of malaria elimination by 2030 . These states are largely located in eastern, north-eastern, and central parts of the country and contribute to $80 \%$ of malaria reported in the country..$^{5}$ Interestingly, these states also have the highest concentration of tribal population. The states with tribal population in the range of $10-29.9 \%$ contributed $59 \%$ of total malaria cases between 2008 and 2012. While, districts with $30 \%$ or more tribal population accounted for $46 \%$ of total malaria cases. ${ }^{6}$ Madhya Pradesh is one such state which has high burden of malaria as well as high concentration of tribal population. ${ }^{5}$

The malaria control programme has been focusing on both preventive and curative aspects of malaria. The role of communities, in terms of accepting, practicing and assimilating these preventive and care seeking behaviours is critical in improving the malaria situation at the local level as well as in eliminating malaria. Further, in the context of increasing resistance of mosquito vectors and malaria parasites to insecticides and drugs respectively, assimilation of these behaviours at community level certainly facilitates the control and elimination efforts. Studies have shown the importance of such behaviours in malaria control and elimination particularly at the grassroots. Literature indicates that correct knowledge and practices in relation to malaria prevention, treatment and control along with correct health-seeking behaviour can minimize the risk factors for malaria as well as can facilitate in malaria elimination. Accordingly, knowledge and practices with respect to the causation, transmission, prevention and treatment of malaria is considered as proxy indicators in the study to examine the extent to which the malaria preventive and care seeking behaviour have been assimilated among the tribal communities.

\section{Materials and Methods}

The paper is based on the data collected through a crosssectional survey in Umaria and Dindori districts of Madhya Pradesh for a larger three-year study, culminating in 2017, which had focused on climate change and malaria. Both these districts are malaria endemic and tribal dominated districts of Madhya Pradesh. Dindori, with 65\%, and Umaria, with $47 \%$ of tribal population ${ }^{7}$ together contributes to $25 \%$ of malaria in the state. ${ }^{8}$

We collected the data from a sample of 482 households, which was derived using the following formula:

$n=[\operatorname{DEFF} * N p(1-p)] /\left[\left(d^{2} / Z^{2}{ }_{1-\alpha / 2}^{*}(N-1)+p *(1-p)\right]\right.$

By substituting the value of $p$ with $50 \%$ for confidence interval 95\% and design effect 2.0 .
A two-stage sampling was used to select the households. In the first stage, a list of blocks was prepared for both the districts and from each block one Primary Health Centre (PHC) having relatively higher malarial load was selected. Accordingly, 7 PHCs from Dindori district and 3 PHCs from Umaria districts were selected. In the second stage, 50 villages with high burden of malaria cases were identified with the help of district program officials (involved in malaria control program) which were spread across these 10 PHCs. For each selected village, a list of households was prepared and ten households were randomly selected. A semi-structured schedule was developed to collect the data.

The study received the ethical approval from the Institutional Ethics Committee. Informed consent was obtained from all the respondents before proceeding with the data collection. Confidentiality was ensured by keeping the respondent anonymous in all stages of data analysis.

The data is analysed using SPSS version 22. Descriptive statistics are used to determine relative frequencies and percentages. Chi-square test is used to determine the associations between different variables. SES index is constructed using the Kuppuswamy scale.

\section{Results}

A total of 482 respondents participated in the study. Majority of them were males $(77.4 \%)$ with a median age of 38 years. Almost one-third of the respondents (32.4\%) were illiterate and very few respondents had higher qualifications like graduations or post-graduations. Majority of the respondents were farmers with $80 \%$ of them belonging to lower socio-economic class (Table 1).

Table I.Socio-demographic Characteristics of the Respondents

\begin{tabular}{|c|c|c|}
\hline Age groups (years) & $\mathbf{n}$ & Percentage \\
\hline $15-24$ & 49 & 10.2 \\
\hline $25-34$ & 120 & 24.9 \\
\hline $35-44$ & 137 & 28.4 \\
\hline $45-54$ & 98 & 20.3 \\
\hline $55+$ & 78 & 16.2 \\
\hline Total & 482 & 100.0 \\
\hline \multicolumn{3}{|c|}{ Sex } \\
\hline Male & 373 & 77.4 \\
\hline Female & 109 & 22.6 \\
\hline Total & 482 & 100.0 \\
\hline \multicolumn{3}{|c|}{ Education } \\
\hline Illiterate & 156 & 32.4 \\
\hline Primary Level & 42 & 8.7 \\
\hline
\end{tabular}




\begin{tabular}{|c|c|c|}
\hline $\begin{array}{l}\text { Upper primary level } \\
\text { (Middle) }\end{array}$ & 154 & 32.0 \\
\hline $\begin{array}{l}\text { Secondary level } \\
\text { (High School) }\end{array}$ & 64 & 13.3 \\
\hline $\begin{array}{l}\text { Senior secondary level } \\
\text { (Intermediate) }\end{array}$ & 41 & 8.5 \\
\hline $\begin{array}{l}\text { Graduation and above } \\
\qquad(\mathrm{PG})\end{array}$ & 25 & 5.2 \\
\hline Total & 482 & 100.0 \\
\hline \multicolumn{3}{|c|}{ Occupation } \\
\hline Unemployed & 31 & 6.4 \\
\hline Agriculture/Farmers & 310 & 64.3 \\
\hline $\begin{array}{l}\text { Permanent government } \\
\text { jobs }\end{array}$ & 19 & 3.9 \\
\hline Self employed & 38 & 7.9 \\
\hline Other (like labour work) & 84 & 17.4 \\
\hline Total & 482 & 100.0 \\
\hline \multicolumn{3}{|c|}{ Socio-economic status } \\
\hline Lower & 43 & 8.9 \\
\hline Upper lower & 340 & 70.5 \\
\hline Lower middle & 70 & 14.5 \\
\hline Upper middle & 29 & 6.0 \\
\hline Upper & 0 & 0 \\
\hline Total & 482 & 100.0 \\
\hline
\end{tabular}

The knowledge of respondents regarding malaria and its prevention is presented in Table 2. Majority of the respondents $(71.2 \%)$ knew that malaria is transmitted through mosquito bite irrespective of the gender $\left(\chi^{2}=\right.$ $0.906, \mathrm{df}=2, p=0.636$ ) and socio-economic status of the respondents $\left(x^{2}=4.535, d f=2, p=0.104\right)$. However, this knowledge was found to be significantly associated with the years of schooling $\left(\chi^{2}=36.30, d f=6, p=0.001\right)$. In terms of respondent's awareness/knowledge about the malaria symptoms, the findings indicate that two-third of the respondents were not aware about them (Table 2).

Only $30 \%$ of the respondents were able to report "fever with chills" or "fever with cold", the most characteristics symptoms of malaria. The awareness/knowledge about the malarial symptoms was also found to be significantly associated with the education level $\left(\chi^{2}=36.73, d f=9, p\right.$ $=0.000)$ and socio-economic status of the respondent $\left(\chi^{2}\right.$ $=12.09, \mathrm{df}=3, p=0.007)$. The findings also indicate that households which had malarial infection in their family had a better knowledge of malarial symptoms as compared to those households where there was no history of malaria infection $\left(x^{2}=12.53, d f=3, p=0.006\right)$. There were 127 households which had reported about having malaria case. Findings indicate that majority of the respondent's use mosquito net bed (65\%) (Table 2). About $57 \%$ of respondents burnt foliage/cow dung cakes as part of preventive measures irrespective of their educational status $\left(x^{2}=3.19, d f=3, p\right.$ $=0.364)$. Statistical test showed an association between the education level and use of mosquito net $\left(\chi^{2}=12.59\right.$, $\mathrm{df}=3, p=0.006)$ as well as use of mosquito repellent $\left(\chi^{2}=\right.$ 21.14, $d f=3, p=0.001$ ).

Table 2.Knowledge and Practice regarding Malaria

\begin{tabular}{|c|c|c|}
\hline Malaria transmission & $\mathbf{n}$ & Percentage \\
\hline Mosquito bite & 343 & 71.2 \\
\hline $\begin{array}{l}\text { Stagnated or dirty water or } \\
\text { unclean surroundings }\end{array}$ & 33 & 6.8 \\
\hline Don't know & 106 & 22.0 \\
\hline Total & 482 & 100.0 \\
\hline \multicolumn{3}{|c|}{ Malaria symptoms } \\
\hline Fever with chills & 70 & 15.0 \\
\hline Fever \& cold & 68 & 14.5 \\
\hline $\begin{array}{c}\text { Others (any one or two: } \\
\text { weakness, vomiting, diarrhoea, } \\
\text { loss of appetite, jaundice, } \\
\text { anaemia, swelling, irritation, } \\
\text { vertigo, illness) }\end{array}$ & 23 & 4.9 \\
\hline Don't know & 321 & 65.6 \\
\hline Total & 482 & 100.0 \\
\hline \multicolumn{3}{|c|}{$\begin{array}{c}\text { Malaria preventive measures at } \\
\text { household level }\end{array}$} \\
\hline Mosquito net & 249 & 64.5 \\
\hline Mosquito repellent & 26 & 6.7 \\
\hline $\begin{array}{l}\text { Covering body by wearing full } \\
\text { clothes }\end{array}$ & 45 & 11.7 \\
\hline $\begin{array}{l}\text { Generating smoke by burning } \\
\text { foliage or cow dung }\end{array}$ & 218 & 56.5 \\
\hline Total & 386 & 100 \\
\hline
\end{tabular}

In $26 \%$ of the households, at least one member had malaria in the last one year. In total, there were 158 people who reportedly had malaria. Among them, $85 \%$ had malaria during the monsoon season, i.e., June-September. About $87 \%$ cases mentioned that laboratory test was conducted to confirm malaria. In terms of seeking the treatment, $92 \%$ of the cases sought treatment for malaria and $6 \%$ of the cases were hospitalized. Majority of the cases had spent up to Rs. 1000 for seeking treatment (78\%) (Table 3). 
Table 3.Malaria Cases

\begin{tabular}{|c|c|c|}
\hline & $\mathbf{n}$ & Percentage \\
\hline $\begin{array}{c}\text { No. of households with malaria } \\
\text { cases }\end{array}$ & 127 & 26 \\
\hline $\begin{array}{c}\text { No. of people who had malaria } \\
\text { cases }\end{array}$ & 158 & 6 \\
\hline $\begin{array}{l}\text { No. of people who sought } \\
\text { treatment }\end{array}$ & 145 & 91.8 \\
\hline $\begin{array}{l}\text { Treatment sought at govt. } \\
\text { facilities }\end{array}$ & 97 & $61.4 \%$ \\
\hline $\begin{array}{l}\text { Treatment sought by Pvt. } \\
\text { facilities (includes private } \\
\text { doctors, clinics, Vaidya/hakim/ } \\
\text { homeopathy) }\end{array}$ & 61 & $38.6 \%$ \\
\hline \multicolumn{3}{|c|}{ Month when individual had malaria } \\
\hline June - September & 135 & 85.4 \\
\hline October - December & 8 & 5.1 \\
\hline Other months & 15 & 9.5 \\
\hline Total & 158 & 100.0 \\
\hline \multicolumn{3}{|c|}{ Laboratory test done to confirm malaria } \\
\hline Yes & 137 & 86.7 \\
\hline No & 21 & 13.3 \\
\hline \multicolumn{3}{|l|}{ Expenses incurred } \\
\hline$<=$ Rs. 500 & 52 & 44.8 \\
\hline Rs. 501 - Rs. 1000 & 38 & 32.8 \\
\hline Rs. 1001 - Rs. 1500 & 8 & 6.9 \\
\hline Rs. 1501 - Rs. 2000 & 18 & 15.5 \\
\hline Total & 116 & 100.0 \\
\hline
\end{tabular}

\section{Discussion}

Correct knowledge and practices in relation to malaria prevention, treatment and control at the community level, more so among vulnerable population, like tribal communities, is an indication of acceptance and assimilation of preventative and care seeking behaviours. This is critical not only in minimizing the risk but also in improving malaria situation at the sub-national level. The findings of this study suggest that there is an assimilation of correct knowledge and practice behaviour among tribal communities. This is important from the malaria control and elimination perspective.

The findings indicate that sizable proportion of the respondents possessed correct knowledge about the transmission of malaria (mosquito bite), irrespective of their gender and socio-economic status. However, the educational background of the respondents had influence on their knowledge. More educated respondents had the correct knowledge. Surprisingly, the knowledge about the most characteristic symptoms of malaria (fever or fever with chills) was limited to only few respondents. Majority not being aware of the characteristics symptoms of malaria is a matter of concern. Education level again had a role in respondents being aware of the malarial symptoms. Similarly, the experience of encountering malaria in the past also had influenced having correct knowledge of malaria symptoms. Respondents who had experienced malaria either at individual or family level had correct knowledge about the symptoms of malaria.

These findings are in concordance with the other studies conducted in tribal population of India, which have found association between the tribal population having correct knowledge about aetiology of the malaria (primarily the role of mosquito in transmitting malaria) as well as being aware of the most characteristics symptoms of malaria (fever/fever with chills) and levels of education. ${ }^{9-13}$ However, our findings are in contradiction with those which state that tribal communities do not possess the correct knowledge about malaria etiology. ${ }^{10,11,14-16}$ The fact that tribal communities have the knowledge about mosquito/mosquito bite being responsible for transmitting malaria is important as then the engagement in practicing preventive behaviours is more. Studies have shown that people do not get engaged in taking up measures that protect them from vector when they have poor knowledge of malaria and its causes. ${ }^{17-19}$ Against the findings about gender differences in having correct knowledge about transmission or symptoms which have been discussed in these studies ${ }^{10,11,12,14}$ our study did not find any statistical significant difference. This could possibly due to variations in methodological approach used in this study and other studies.

In terms of practice, particularly related to preventive measure followed at individual level, findings from the study indicate the acceptance of insecticide treated nets within the tribal community (as good proportion of the respondents reportedly using it). It is significant as use of insecticide treated nets, in endemic areas, is recommended under the programme and evidence suggests that use of insecticide treated mosquito net by the people not only improves the malaria situation at the local level but can consequently help in lowering the malaria burden. Studies conducted in other parts of India have also reported the usage of insecticide treated nets among tribal population. ${ }^{20-23}$ The role of education in using insecticide treated nets was evident in our study too with the usage being high among respondents having higher level of education.

In our study, majority of respondents were also found to be practicing foliage/cow dung cake burning as part 
of prevention. Interestingly, this practice was not limited to only less educated respondents but respondents with higher educational qualifications also followed this. Burning foliage/cow dung cakes being effective in preventing malaria could be contested but majority following it in the study area, irrespective of educational status, suggest tribal community believing in its efficacy. Other studies have also reported tribal communities do follow this practice.

Treatment seeking behaviour among tribal group is complex and multiple factors determine the appropriate behaviour. ${ }^{14,24,25}$ Studies have also pointed out tribal population preference towards localized healers for treatment. ${ }^{26-28}$ However, in this study, a good proportion of respondent, who had malaria, sought treatment at government health facilities. A sizable proportion of the malaria patients also sought treatment from private doctors. This is of concern as presence of unregistered medical practitioners in tribal areas is quite common and possibilities of these private doctors being unregistered medical practitioners are high. Getting diagnosed and treated from these practitioners could be risky and dilute the programme efforts as studies have pointed out that these practitioners lack required knowledge of diagnosing and treating malaria. ${ }^{29}$ Respondent also reported about expenses being incurred towards the treatment.

Our study has a limitation in terms of generalizing the results to other tribal areas of the State and country as the study areas were confined to two districts alone of Madhya Pradesh. Furthermore, the non-randomized selection of village can bias the results. Since the selected villages had high malaria burden, the program activities could have been implemented in more rigorous way, which could have influenced the results. Though obvious, any conclusive submission towards the impact of programme activities is not justifiable as the study was a cross-section study which by design restricts establishing any causal and effect relationship. However, this could be an area of further research.

\section{Conclusion}

We conclude that tribal groups generally possess knowledge about malaria and engage in desirable behaviours for its management and control, which points to their acceptance and assimilation of the government programme. This offers a firm footing for building up community engagement initiatives for prevention and control as well as strengthening facilities for early case detection and management in malaria endemic tribal areas. It is high time that concerted, evidence based, settings differentiated efforts were developed and deployed for our tribal population, so that malaria elimination becomes a reality.

\section{Acknowledgement}

We express our sincere thanks to the DST, Government of India, for funding the study.

\section{Conflicting Interest: None \\ References}

1. World Health Organization. World malaria report, 2019. Available from: https://apps.who.int/iris/rest/ bitstreams/1262394/retrieve. Last accessed on 2020 April 30.

2. World Health Organization. South-East Asia Region; efforts must continue as risks persist: World Health Organization. 4 December 2019 News release India (SEAR/PR/1721). Available from: http://who.int/ southeastasia/news/detail/04-12-2019-malaria-onthe-decline-in-who-south-east-asia-region-effortsmust-continue-as-risks-persist-who. Last accessed on 2020 March 25.

3. World malaria day. 2018. Available from: https://www. nhp.gov.in/world-malaria-day-2018_pg. Last accessed on 2019 July 22.

4. Government of India. National Framework for Malaria Elimination (NFME) 2016-2030, Ministry of Health and Family Welfare, Government of India. Available from: https://apps.who.int/iris/bitstream/ handle/10665/246096/national_framework_malaria_ elimination_india_2016_2030.pdf. Last accessed on 2019 July 22.

5. Strategic plan for malaria control in India 2012-2017: a five-year strategic plan. Directorate of National Vector Borne Disease Control Programme, Directorate General of Health Services, Ministry of Health \& Family Welfare, Government of India. Available from: http://www.nvbdcp.gov.in/WriteReadData/ 1892s/38633988231543495303.pdf. Last accessed on 2019 July 22.

6. Sharma RK, Thakor HG, Saha KB, Sonal GS, Dhariwal AC, Singh N. Malaria situation in India with special reference to tribal areas. Indian J Med Res. 2015 May;141(5):53745. [PubMed] [Google Scholar]

7. Census. Registrar General of India, Ministry of Home Affairs, Government of India. 2011. Available from: http://www.censusindia.gov.in/2011census/.

8. Singh N. Tribal malaria, an update on changing epidemiology. Available from: nirth.res.in. Accessed on 10.11.2019.

9. Phukan P. Awareness and practices in relation to malaria in a tribal area in Kamrup District, Assam. Indian J Public Health. 2009 Oct-Dec;53(4):237-9. [PubMed] [Google Scholar]

10. Sharma AK, Bhasin S, Chaturvedi S. Predictors of 
knowledge about malaria in India. J Vector Borne Dis. 2007 Sep;44:189-97. [PubMed] [Google Scholar]

11. Singh RK, Haq S, Dhiman RC. Studies on knowledge, attitude and practices in malaria endemic tribal areas of Bihar and Jharkhand, India. J Trop Dis. 2013;1:110. [Google Scholar]

12. Kumar S, Debbarma A. Predictors of knowledge towards malaria of rural tribal communities in Dhalai District of Tripura, India. Mymensingh Med J. 2013 Oct;22(4):82532. [PubMed] [Google Scholar]

13. Panda R, Kanhekar LJ, Jain DC. Knowledge, attitude and practice towards malaria in rural tribal communities of south Bastar district of Madhya Pradesh. J Commun Dis. 2000 Sep; 32(3):222-7. [PubMed] [Google Scholar]

14. Das A, Gupta RD, Friedman J, Pradhan MM, Mohapatra CC, Sandhibigraha D. Community perceptions on malaria and care-seeking practices in endemic Indian settings: policy implications for the malaria control programme. Malar J. 2013 Jan;12:39. [PubMed] [Google Scholar]

15. Singh TG, Singh RK, Singh EY. A study of knowledge about malaria and treatment seeking behaviour in two tribal communities of Manipur. Indian J Public Health. 2003 Apr-Jun;47(2):61-5. [PubMed] [Google Scholar]

16. Sharma SK, Jalees S, Kumar K, Rahman SJ. Knowledge, attitude and beliefs about malaria in a tribal area of Bastar district (Madhya Pradesh). Indian J Public Health. 1993 Oct-Dec;37(4):129-32. [PubMed] [Google Scholar]

17. Vundule $C$, Mharakurwa S. Knowledge, practices, and perceptions about malaria in rural communities of Zimbabwe: relevance to malaria control. Bull World Health Organ. 1996;74(1):55-60. [PubMed] [Google Scholar]

18. Agyepong IA. Malaria: ethnomedical perceptions and practice in an Adangbe farming community and implications for control. Soc Sci Med. 1992 Jul;35(2):131-7. [PubMed] [Google Scholar]

19. Yeneneh H, Gyorkos TW, Joseph L, Pickering J, Tedla S. Antimalarial drug utilization by women in Ethiopia: a knowledge-attitudes-practice study. Bull World Health Organ. 1993;71(6):763-72. [PubMed] [Google Scholar]

20. Vijayakumar KN, Gunasekaran K, Sahu SS, Jambulingam P. Knowledge, attitude and practice on malaria: a study in a tribal belt of Orissa state, India with reference to use of long lasting treated mosquito nets. Acta Trop. 2009 Nov;112(2):137-42. [PubMed] [Google Scholar]

21. Jambulingam $P$, Gunasekaran K, Sahu S, Vijayakumar T. Insecticide treated mosquito nets for malaria control in India-experience from a tribal area on operational feasibility and uptake. Mem Inst Oswaldo Cruz. 2008 Mar;103(2):165-71. [PubMed] [Google Scholar]

22. Gunasekaran K, Sahu SS, Vijayakumar KN, Jambulingam P. Acceptability, willing to purchase and use long lasting insecticide treated mosquito nets in Orissa State, India. Acta Trop. 2009 Nov;112(2):149-55. [PubMed] [Google Scholar]

23. Prakash A, Bhattacharyya DR, Mohapatra PK, Goswami BK, Mahanta J. Community practices of using bed nets $\&$ acceptance $\&$ prospects of scaling up insecticide treated nets in north-east India. Indian J Med Res. 2008 Nov;128(5):623-9. [PubMed] [Google Scholar]

24. Das $A$, Ravindran TKS. Factors affecting treatment seeking for febrile illness in a malaria endemic block in Boudh district, Orissa, India: policy implications for malaria control. Malar J. 2010 Dec 30;9:377. [PubMed] [Google Scholar]

25. Mazumdar S. Prevalence, risk factors and treatmentseeking behaviour for malaria: the results of a case study from the Terai region of West Bengal, India. Ann Trop Med Parasitol. 2011 Apr;105(3):197-208. [PubMed] [Google Scholar]

26. Sundararajan R, Kalkonde Y, Gokhale C, Greenough PG, Bang A. Barriers to malaria control among marginalized tribal communities: a qualitative study. PLoS One. 2013 Dec 20;8(12):e81966. [PubMed] [Google Scholar]

27. Singh N, Singh MP, Saxena A, Sharma VP, Kalra NL. Knowledge, attitude, beliefs and practices (KABP) study related to malaria and intervention strategies in ethnic tribals of Mandla (Madhya Pradesh). Curr Sci. 1998;75:1386-90. [Google Scholar]

28. Nanda N, Bhatt RM, Sharma SN, Rana PK, Kar NP, Sharma A, Adak T. Prevalence and incrimination of Anopheles fluviatilis species S (Diptera: Culicidae) in a malaria endemic forest area of Chhattisgarh state, central India. Parasit Vectors. 2012 Sep 28;5:215. [PubMed] [Google Scholar]

29. Singh MP, Chand SK, Saha KB, Singh N, Dhiman RC, Sabin LL. Unlicensed medical practitioners in tribal dominated rural areas of central India: bottleneck in malaria elimination. Malar J. 2020 Jan 14;19(1):18. [PubMed] [Google Scholar] 